\title{
The influence of context on patterns of corrective feedback and learner uptake: a comparison of CLIL and immersion classrooms
}

\section{Ana Llinares \& Roy Lyster}

To cite this article: Ana Llinares \& Roy Lyster (2014) The influence of context on patterns of corrective feedback and learner uptake: a comparison of CLIL and immersion classrooms, The Language Learning Journal, 42:2, 181-194, DOI: 10.1080/09571736.2014.889509

To link to this article: http://dx.doi.org/10.1080/09571736.2014.889509

曲 Published online: 14 Mar 2014.

Submit your article to this journal $\pi$

Џll Article views: 1013

Q View related articles $\asymp$

View Crossmark data ־

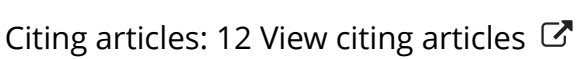




\title{
The influence of context on patterns of corrective feedback and learner uptake: a comparison of CLIL and immersion classrooms
}

\author{
Ana Llinares $^{\mathrm{a} *}$ and Roy Lyster ${ }^{\mathrm{b}}$ \\ ${ }^{a}$ Department of English Studies, Universidad Autónoma de Madrid, Madrid, Spain; ${ }^{b}$ Department of \\ Integrated Studies in Education, McGill University, Montreal, Canada
}

\begin{abstract}
This study compares the frequency and distribution of different types of corrective feedback (CF) (recasts, prompts and explicit correction) and learner uptake in 43 hours of classroom interaction at the 4th-5th grade level across three instructional settings: (1) two content and language integrated learning (CLIL) classrooms in Spain with English as the target language; (2) four French immersion (FI) classrooms in Quebec (using published data from Lyster and Ranta 1997); and (3) three Japanese immersion (JI) classrooms in the US (using published data from Lyster and Mori 2006). The findings revealed that teachers in all three settings used recasts, prompts and explicit correction in similar proportions, with recasts being the most frequent, followed by prompts then explicit correction. However, in the CLIL and JI classrooms, the majority of learner repair moves followed recasts, whereas the majority of repair moves in FI classrooms followed prompts. The similarities and differences across contexts are discussed in terms of the different types of recasts used by the teachers (i.e. didactic recasts in CLIL and JI; conversational recasts in FI), as well as in terms of context-specific influences and the teachers' professional trajectories.
\end{abstract}

\section{Introduction}

Content-based language teaching (CBLT) is an umbrella term used to refer to instructional approaches in which non-linguistic curricular content such as science or mathematics is taught to students through the medium of a language that they are learning concurrently as an additional language. Met (1998) described a range of CBLT settings along a continuum varying from content-driven to language-driven. At the content-driven end of the continuum are the programmes that are the topic of the present study: immersion and content and language integrated learning (CLIL) programmes, both of which share the goal of developing functional proficiency in an additional language by teaching content through that language.

An important issue in programmes situated towards the content-driven end of the continuum is whether students learn the language incidentally as they learn academic content. Twenty-five years ago, Swain (1988) proposed that content teaching on its own was not necessarily good language teaching and needed to be complemented and manipulated to maximise language learning; since then, researchers have concurred that for CBLT to be effective, it must be language-rich and discourse-rich (e.g. Allen et al. 1990;

*Corresponding author. Email: ana.llinares@uam.es 
Dalton-Puffer 2007; Duff 2001; Genesee 1987; Hoare and Kong 2008; Lyster 2007; Musumeci 1996).

The instructional integration of both language and content, however, is no simple matter. One way of doing so, from a systemic-functional linguistic perspective, is to emphasise how linguistic features of disciplinary texts construe particular kinds of meanings (Llinares, Morton and Whittaker 2012). From a similar perspective, Kong's (2009) comparative study revealed that effective CBLT teachers explored content with students from multiple perspectives and conveyed complex subject matter through knowledge relationships (i.e. cause-effect, hypothesis and comparison) that were actualised in target language forms made salient by the teacher through consistent and explicit use. In the same vein, Lyster's (2007) proposal for a counterbalanced approach to CBLT calls for a more systematic integration of form-focused and content-based instruction in order to ensure continued language growth in immersion settings. One way for teachers to counterbalance both language and content is to integrate into subject-matter instruction a reactive approach to focus on form, that is, through the provision of corrective feedback $(\mathrm{CF})$.

\section{Corrective feedback and learner uptake}

Based on descriptive studies of teacher-student interaction (Lyster and Mori 2006; Lyster and Ranta 1997), CF moves can be classified as one of three types: explicit correction, recasts or prompts. A recast is 'the teacher's reformulation of all or part of a student's utterance, minus the error' (Lyster and Ranta 1997: 46). Explicit correction also provides the correct form but, unlike recasts, 'clearly indicates that what the student had said was incorrect' (Lyster and Ranta 1997: 46). In contrast, prompts - which include elicitation, metalinguistic clues, clarification requests and repetition - withhold correct forms and instead provide clues to prompt students to self-repair. With respect to linguistic evidence, explicit correction provides both negative and positive evidence; prompts provide only negative evidence, whereas recasts provide positive evidence and also provide negative evidence if the learner perceives the feedback as an indication that an error has occurred.

Teachers' CF can be followed either by learner uptake or no uptake (i.e. topic-continuation moves). Learner uptake refers to a range of possible responses made by students following CF. Uptake is defined as a discourse move and not as an instance of acquisition, although some researchers have suggested that uptake may be 'related to learners' perceptions about feedback at the time of feedback' (Mackey, Gass and McDonough 2000: 492). Lyster and Ranta (1997) identified learner uptake as either: (1) utterances still in need of repair; or (2) utterances with repair. Learner repair entails the correct reformulation of an error whereas learner responses still in need of repair include simple acknowledgements such as 'yes', hesitations, off-target responses, partial repair and occurrences of either the same or a different error. Learner repair can be either a repetition or self-repair and these different types of immediate repair are specific to one type of CF or another: recasts and explicit correction can lead only to repetition of correct forms by students, whereas prompts can lead, not to repetition, but either to self-repair or peer-repair.

Classroom studies designed to compare the effects of recasts and prompts have shown benefits for both, with some benefits for prompts over recasts, but not to the extent predicted (e.g. Ammar and Spada 2006; Lyster 2004; Yang and Lyster 2010). The results have revealed important nuances in the effects of different types of CF worthy of further investigation, but also led Lyster, Saito and Sato (2013:21) in their recent review of research on CF in classroom settings to conclude that 'it may not be necessary or even possible for researchers to identify the single most effective CF strategy', suggesting instead that teachers need to know how to 
orchestrate 'a wide range of CF types befitting the instructional context'. They called for replication studies to consider the generalisability of previous research and to further illustrate how CF patterns are differentially affected by instructional setting. Hence the goal of the present study, which is to compare patterns of CF and learner uptake in CLIL classrooms in Spain with such patterns previously observed in French immersion (FI) classrooms in Canada and Japanese immersion (JI) classrooms in the US.

\section{The present study}

The present study examines CF and learner uptake patterns in three instructional settings, specifically drawing attention to differential proportions of learner repair associated with specific CF types. The aim is not to assess the effects of different types of CF on language development but rather to describe discourse patterns across CLIL and immersion settings. This study is one of the first contributions to provide insights into the similarities and differences between CLIL and immersion, specifically with respect to classroom interactional patterns involving $\mathrm{CF}$ and learner uptake.

Building on Lyster and Mori's (2006) comparison of patterns of interactional feedback in two different immersion programmes, the present study presents a three-way comparison of the two immersion settings with parallel data in a CLIL programme in Madrid, Spain. The research questions are the following:

(1) How are recasts, prompts and explicit correction distributed across CLIL, FI and JI classrooms at the 4th-5th-grade level?

(2) What is the extent of learner uptake and repair associated with each CF type across contexts?

(3) What factors may contribute to similarities and differences across contexts?

\section{Method}

This study compares patterns of CF and learner uptake at the 4th-5th-grade level in three instructional settings comprising a total of nine classrooms: (1) two CLIL classrooms in Spain with English as the target language; (2) four FI classrooms in Quebec (Lyster 1998a; Lyster and Ranta 1997); and (3) three JI classrooms in the US (Lyster and Mori 2006; Mori 2002). The total database comprises 43.1 hours of classroom interaction distributed as follows: 10 hours in CLIL, 18.3 hours in FI and 14.8 hours in JI.

\section{Contexts and participants}

\section{CLIL classrooms}

The CLIL data are from two 4th-grade classrooms at two different schools, each participating in a different bilingual programme in the Comunidad de Madrid. The teacher at one school was a native speaker of Spanish with 10 years of teaching experience (six as an English as a foreign language (EFL) teacher and four as a CLIL teacher). Her class consisted of 22 students, all of them native speakers of Spanish. The teacher at the other school, also a native speaker of Spanish, had 13 years of teaching experience, eight as an EFL teacher and five as a CLIL teacher. Her class had 15 students, all of them native speakers of Spanish except for three children from Romania, Morocco and Brazil. In both programmes, students are taught in English for between 40 and $50 \%$ of the school time, starting in first grade. 
Approximately, half of this time is devoted to EFL and the other half to subject-matter instruction.

\section{FI classrooms}

The data from FI classrooms used in the present study are from the four classrooms described in detail in Lyster and Ranta (1997) and subsequently investigated in Lyster and Mori (2006). There are three 4th-grade classes and one 4th/5th-grade class. One of the 4th-grade classrooms belonged to a school board with an early total immersion programme, in which the students' school day had been $80 \%$ in French and 20\% in English since 1 st grade. The other three classes belonged to a school board with a middle immersion programme beginning in 4th grade, at which point the school day became $60 \%$ in French and $40 \%$ in English (and had been only 20\% in French from 1 st to 3rd grade). The teacher in the early immersion classroom was a native speaker of French and had an extensive teaching experience: 14 years at the secondary level teaching French L1 and seven years in FI at the elementary level. The 30 students in this class came from a variety of language backgrounds, including six who spoke French at home. Students in the middle immersion programme mainly came from English-speaking homes. Their class sizes were 26, 24 and 24. Of their three teachers, one was a female English-French bilingual with 15 years of teaching experience, another was a native speaker of French with eight years of teaching experience, which included two years in French L1 and six in FI, and the only male participant was an English-French bilingual who had taught for five years, which included two years in English and three years in FI.

\section{Japanese immersion classrooms}

The data from the three JI classrooms appear in a larger classroom study described by Mori (2002) and were used in Lyster and Mori's (2006) comparison of FI and JI classrooms. Of the three JI classrooms, two were 4th-grade classes taught by the same teacher and the third was a 5th-grade class taught by a different teacher. All three classes were part of an early partial JI programme at an elementary school in the US. The JI programme began in kindergarten, which students attended for 2.5 days per week and where instruction was approximately $90 \%$ in Japanese and $10 \%$ in English. From 1st grade on, their instruction was about $50 \%$ in Japanese and $50 \%$ in English. The 4th-grade teacher had taught at the JI school for seven years and, prior to that, had taught for six years at the elementary level in Japan. The 5th-grade teacher had taught for nine years at the JI school, prior to which she had taught Japanese for one year at a junior high school, one year at a senior high school and six years at the college level. Both teachers were Japanese-born female native speakers of Japanese with native-like competence in English. The 4th-grade classes each consisted of 20 students, while the 5th-grade class consisted of 29 students. All students were native speakers of English, coming from English-speaking homes with parents whose socio-economic status was considered average.

\section{Data collection and analysis}

In the CLIL classrooms, 12 lessons totalling 10 hours of teacher-student interaction were observed in science and social science classes, taught throughout primary school as one subject called Conocimiento del Medio Natural, Social y Cultural. The interaction was video-recorded and then transcribed by a native speaker of English and verified by a 
native speaker of Spanish with a high level of competence in English. In the four FI classrooms, interaction was audio-recorded and then transcribed by a native or native-like speaker of French and all transcripts were verified at least once by a second transcriber. The corpus includes 27 lessons totalling 18.3 hours: 7.8 hours of French language arts and 10.5 hours of subject-matter instruction (science, social studies and maths). Interaction in the three JI classrooms was both audio- and video-recorded. The audio-recordings were transcribed by a native speaker of Japanese and then verified by a second transcriber who was also a native speaker of Japanese. The JI data, totalling 14.8 hours, include Japanese language arts lessons (10.9 hours), subject-matter lessons (2.1 hours) and other activities involving discussions before and after regular lessons (1.7 hours).

The main unit of analysis was the error treatment sequence identified in Lyster and Ranta (1997). They distinguished three types of CF (explicit correction, recasts and prompts) and examined learner uptake following each CF type and whether this uptake included the students' repair or not. The CLIL data were coded by an expert in classroom interaction, with a second researcher being consulted and were analysed with the help of the UAM-Corpus tool (O'Donnell 2011). Interrater reliability tests performed on $25 \%$ of the CLIL data yielded an agreement level of .88. As reported in Lyster and Mori (2006), the immersion data were coded by two native or native-like speakers of French in the case of the French data and by a native speaker of Japanese in the case of the Japanese data. Tests of interrater reliability conducted on a subset of $15 \%$ of the FI data and $23 \%$ of the JI data yielded levels of agreement of .84 and .95 , respectively. The analysis of the FI data was carried out with Computer Aided Linguistic Analysis (COALA) (Thornton and Pienemann 1994) whereas the JI data were imported into the Child Language Data Exchange System (CHILDES) for Japanese (Oshima-Takane et al. 1998).

\section{Results}

This section reports the quantitative results to answer the first two research questions pertaining to the distribution of CF types and the extent of learner uptake and repair across the three instructional settings. The third research question concerning the factors influencing the observed patterns will be addressed in the discussion section.

The percentage distribution and number of occurrences of each CF type (prompts, recasts and explicit correction) for each context appear in Table 1 and the percentage distribution is displayed in Figure 1. The proportion of CF types is similar in all three settings, with recasts occurring more frequently than prompts, which occur more frequently than explicit correction.

The percentage distribution and number of occurrences of uptake following each CF type across contexts appear in Table 2 and the percentage distribution is displayed graphically in Figure 2. The patterns in the CLIL and JI classrooms are very similar, with $67 \%$ and $61 \%$ of the uptake in these contexts, respectively, following recasts. In contrast, only $32 \%$ of the uptake in FI classrooms followed recasts whereas $62 \%$ followed prompts.

Table 1. Percentage distribution (and occurrences) of CF moves.

\begin{tabular}{lllc}
\hline & CLIL $(n=298)$ & FI $(n=635)$ & JI $(n=259)$ \\
\hline Prompts & $29 \%(86)$ & $38 \%(244)$ & $26 \%(66)$ \\
Recasts & $57 \%(170)$ & $54 \%(345)$ & $65 \%(169)$ \\
Explicit correction & $14 \%(42)$ & $7 \%(46)$ & $9 \%(24)$ \\
\hline
\end{tabular}




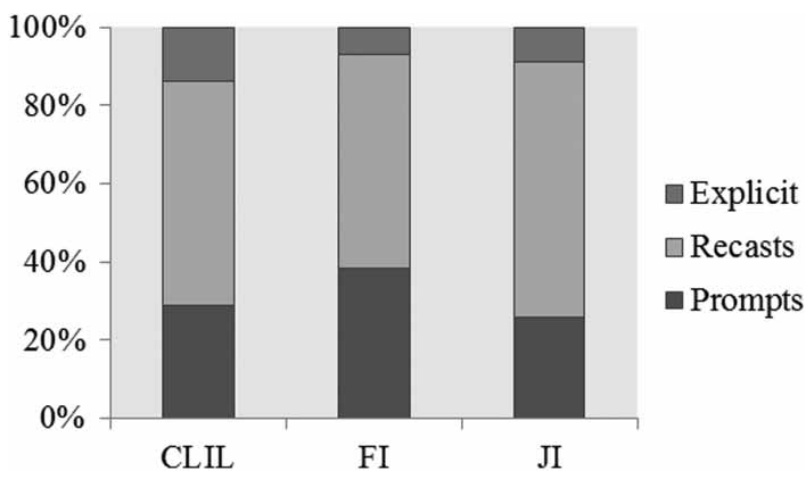

Figure 1. Percentage distribution of CF types across contexts.

Table 2. Percentage distribution (and occurrences) of uptake moves.

\begin{tabular}{lccc}
\hline & CLIL $(n=191)$ & FI $(n=348)$ & JI $(n=198)$ \\
\hline Following prompts & $28 \%(56)$ & $62 \%(215)$ & $30 \%(59)$ \\
Following recasts & $67 \%(135)$ & $32 \%(110)$ & $61 \%(121)$ \\
Following explicit correction & $5 \%(10)$ & $7 \%(23)$ & $9 \%(18)$ \\
\hline
\end{tabular}

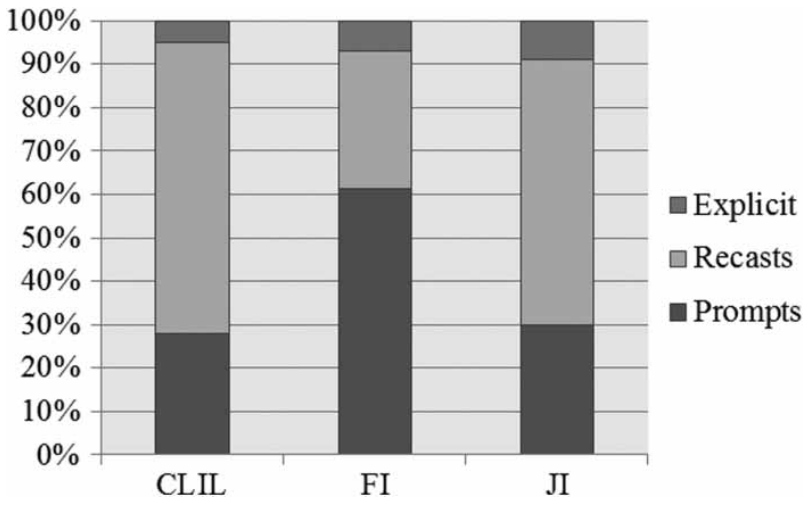

Figure 2. Percentage distribution of uptake after each CF type.

The uptake patterns are reflected in the percentage distribution of repair following each CF type, as displayed in Table 3 and Figure 3. That is, whereas 53\% of the repair in FI classrooms followed prompts and $38 \%$ followed recasts, the reverse pattern emerged in CLIL and JI classrooms, with $77 \%$ and $68 \%$ of all repair in each setting, respectively, following recasts.

Following Lyster and Mori's (2006) comparison of FI and JI classrooms, another way of analysing these data is to display the percentage distribution of uptake in terms of its presence (as repair or needs-repair) or absence after each CF type for each setting, as seen in Table 4 and illustrated in Figure 4. Homing in on the proportion of repair following each CF type reveals that in CLIL classrooms, recasts were much more effective than either prompts or explicit correction at leading to immediate repair (51\% vs $20 \%$ and $22 \%$, respectively). The reverse pattern occurred in FI classrooms, where recasts were by far 
Table 3. Percentage distribution (and number) of repair moves.

\begin{tabular}{lccc}
\hline & CLIL $(n=113)$ & FI $(n=175)$ & JI $(n=124)$ \\
\hline Following prompts & $15 \%(17)$ & $53 \%(93)$ & $23 \%(28)$ \\
Following recasts & $77 \%(87)$ & $38 \%(66)$ & $68 \%(84)$ \\
Following explicit correction & $8 \%(9)$ & $9 \%(16)$ & $10 \%(12)$ \\
\hline
\end{tabular}

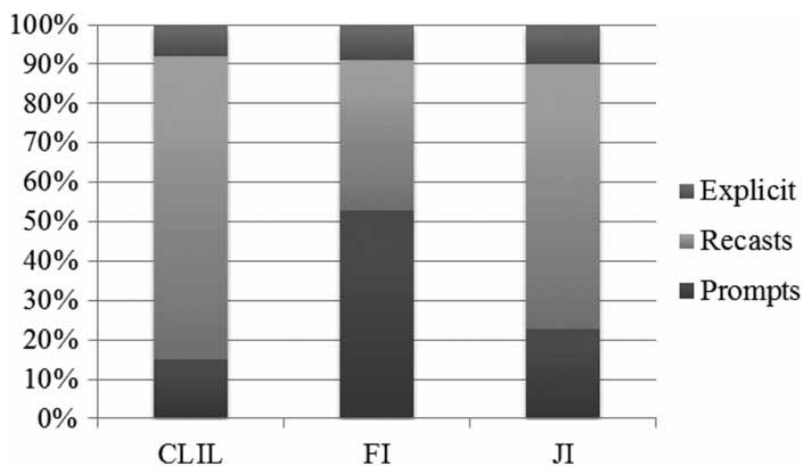

Figure 3. Percentage distribution of repair after each CF type.

Table 4. Percentage distribution (and occurrences) of uptake (repair and needs-repair) and no uptake after $\mathrm{CF}$ types $(\mathrm{PR}=$ prompts; $\mathrm{RE}=$ recasts; $\mathrm{EX}=$ explicit correction $)$.

\begin{tabular}{|c|c|c|c|c|c|c|c|c|c|}
\hline & \multicolumn{3}{|c|}{ CLIL $(n=298)$} & \multicolumn{3}{|c|}{ FI $(n=635)$} & \multicolumn{3}{|c|}{$\mathrm{JI}(n=259)$} \\
\hline & PR & $\mathrm{RE}$ & EX & PR & $\mathrm{RE}$ & EX & PR & $\mathrm{RE}$ & EX \\
\hline Repair & $20 \%(17)$ & $51 \%(87)$ & $22 \%(9)$ & $38 \%(93)$ & $19 \%(66)$ & $35 \%(16)$ & $42 \%(28)$ & $50 \%(84)$ & $50 \%(12)$ \\
\hline Needs repair & $45 \%$ & $28 \%(48)$ & $2 \%$ & $50 \%(122)$ & $13 \%(44)$ & $15 \%(7)$ & $47 \%(31)$ & $22 \%$ & $25 \%(6)$ \\
\hline No uptake & $35 \%(30)$ & $21 \%(35)$ & $76 \%(32)$ & $12 \%(29)$ & $68 \%(235)$ & $50 \%(23)$ & $11 \%(7)$ & $28 \%(48)$ & $25 \%(6)$ \\
\hline
\end{tabular}

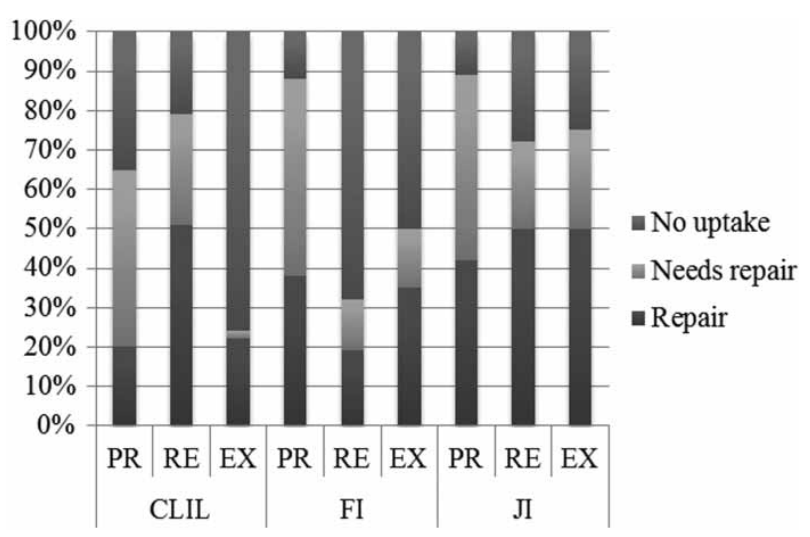

Figure 4. Percentage distribution of repair, needs repair and no uptake after each CF type. 
the least effective relative to prompts and explicit correction (19\% vs $38 \%$ and $35 \%$, respectively). In JI classrooms, recasts, prompts and explicit correction all led to similar proportions of repair $(50 \%, 42 \%$ and $50 \%$, respectively). In addition, JI classrooms displayed the overall lowest rate of no-uptake moves following CF compared to the other two contexts. Finally, with respect to needs-repair moves, the highest proportion in all three contexts followed prompts: $45 \%$ in CLIL, $50 \%$ in FI and $47 \%$ in JI.

\section{Discussion}

In response to our first research question concerning the distribution of recasts, prompts and explicit correction across the three settings, the CF types were proportionately similar in CLIL, FI and JI classrooms: recasts were the most frequent $(57 \%, 54 \%$ and $65 \%$, respectively) followed by prompts $(29 \%, 38 \%, 26 \%$, respectively) then explicit correction $(14 \%$, $7 \%$ and $9 \%$, respectively). In response to our second research question concerning the amount of uptake and repair produced by students immediately following $\mathrm{CF}$, one might expect the pattern to mirror the amount of each CF type used by teachers, with the greatest amount of uptake and repair associated to recasts, then prompts, then explicit correction. Such was the case in the CLIL and JI classrooms, where the majority of repair moves followed recasts $(77 \%$ and $68 \%$, respectively); however, the majority of repair moves in FI classrooms (53\%) followed prompts. The CLIL and JI classrooms proved more similar than did JI and FI classrooms, therefore, at least with respect to repair following recasts. They differ, however, in that repair rates in the JI classrooms were similarly high after all CF types (42\% after prompts, 50\% after recasts and 50\% explicit correction), whereas repair rates in CLIL classrooms were relatively low following prompts (20\%) and explicit correction (22\%). This pattern was reversed in the FI classrooms where the low rate of repair after recasts $(19 \%)$ was countered by relatively higher and similar rates of repair after prompts (38\%) and explicit correction (35\%).

Our discussion is devoted to exploring our third research question, which asked what factors might have contributed to the patterns revealed by the quantitative results. In discussing these results, we first home in on recasts (specifically on different types of recasts), because they proved to be the most frequent type of $\mathrm{CF}$ in all three contexts and, in many respects, might be considered well-tuned to the objectives of CLIL and immersion programmes. That is, recasts serve to: (1) maintain the flow of communication; (2) keep students' attention focused on content; and (3) enable learners to participate in interaction that requires linguistic abilities exceeding their current developmental level (Lyster 2007). We then focus on both the differences and similarities associated with the CLIL, FI and JI classrooms and their respective teachers to provide support for our interpretations of the teacher feedback and learner repair patterns observed across contexts.

\section{Conversational vs didactic recasts}

To interpret our findings, we draw on Sheen and Ellis's (2011) distinction between conversational and didactic recasts (i.e. implicit and explicit recasts, respectively; see Ellis and Sheen 2006). Conversational recasts implicitly reformulate a student utterance in an attempt to resolve a communication breakdown and often take the form of confirmation checks, whereas didactic recasts reformulate a student utterance in the absence of a communication problem and thus with an explicitly corrective purpose. Thus, in contrast to researchers characterising recasts unconditionally as implicit CF (e.g. Long 1996; Long and Robinson 1998), other researchers contend that recasts range from implicit to 
explicit in accordance with context, linguistic targets, length and number of changes (Ellis and Sheen 2006; Nicholas, Lightbown and Spada 2001; Sato 2011; Sheen 2004, 2006). One way to explain the low rate of repair following recasts in FI classrooms and the higher rates in CLIL and JI classrooms (following Sheen 2006) is to consider recasts in FI as more implicit and conversational in nature and those in CLIL and JI as more explicit and didactic in nature. To illustrate this, we have extracted an error treatment sequence from each instructional setting that portrays a prototypical way of recasting in that setting.

The first example, taken from Lyster and Mori (2006: 291-292), represents a typical recast in the FI context that functions conversationally and leads to no immediate repair:

S: Nous sommes allés au Biodôme parce que ma grand-mère elle a jamais allé à là-bas

[We went to the Biodome because my grandmother never goed to there.]

T: Elle était jamais allée.

[She had never gone.]

S: Puis on a allé à /Jungle Adventure/et on a gagné des prix.

[Then we goed to Jungle Adventure and we won prizes.]

T: C'est quoi ça?

[What is that?]

The student's error in choice of auxiliary and tense ('elle a jamais allé') is recast by the teacher ('Elle était jamais allée'), but there is no repair as the student simply continues recounting his March break activities without repeating the recast. Not only does the student not repeat the teacher's recast, as he proceeds he makes a similar error ('on a allé'), which the teacher ignores and instead asks the student to elaborate on the content of his message ('C'est quoi ça?), thus reinforcing the conversational nature of this exchange.

The second example, by way of contrast, is taken from the CLIL context during a similar type of personal account in which the teacher is much more consistent in recasting the student's errors:

S: On Sunday I go to a

T: I went to

S: I go to a

T: I went

S: I went to a ... How do you say exposición [exhibition]?

T: Exposition, exhibition.

S: Exhibition and I find and I found a ... a ... person that that that is making with two, ... with two ... dos palos [two sticks]

$\mathrm{T}$ : She was making

S: She was making glass

The teacher's initial recast ('I went to') is not repeated by the student and is instead followed by a needs-repair move containing the same error ('I go to'). The teacher, then, provides a similar recast but, this time, she makes it more salient by placing the correct verb in final position ('I went'). This more explicit recast is followed by the student's repair. The didactic function of the recast seems to have succeeded in increasing the student's awareness of pasttense forms as evidenced in her next turn, where the student makes a similar error with the present-tense form 'find' but she immediately repairs it with the correct past-tense form ('found'). This is followed by yet another use of the present tense, which the teacher again recasts ('she was making') and which is repaired by the student as well. Other 
recasts in the CLIL context that led to successful repair tended to be similar to those identified by Sheen (2006) as explicit: short recasts in declarative form with falling intonation (see also Loewen and Philp 2006).

The third example occurred in a JI classroom and was considered by Lyster and Mori (2006: 292) to be representative of recasting in that context:

St: basha o irete to, um, um, trail ni mottearimasu

[They put the wagon in it and, um, um, have had it into the trail.]

T: ikimasu, motte: ikimasu.

[They go, they bring it to the trail.]

St: motteikimasu.

[They bring it to the trail.]

T: basha no naka ni irete oregon trail ni motteiku. dakara ie no naka ni okimasen. wakaru?

[They put it in the wagon and bring it to the trail. So they don't put it in the house. Do you understand?]

The teacher's recast ('they bring it to the trail') it followed by the student's repair move ('they bring it to the trail). Following the student's repair, the teacher reformulates all the student's first turn, which included several errors, and then elaborates ('So they don't put it in the house'), before concluding with a comprehension check ('Do you understand?'). We classify this as a didactic recast given not only the instance of successful uptake but also the teacher's follow-up moves, which contain another reformulation, an elaboration and a confirmation check.

\section{Differences and similarities across contexts}

One important finding yielded by the present study is that analyses of classroom interaction specifically entailing CF and learner uptake patterns do not unequivocally distinguish CLIL classrooms from immersion classrooms. That is, JI classrooms had more in common with CLIL classrooms than with FI classrooms. This can be explained in part by the similarities in the design of the CLIL classrooms in Madrid and the JI classrooms in the US: that is, both allotted $50 \%$ of the curriculum to instruction through the target language and both target languages can be considered foreign languages. It seems then that, in the same way that the design of CLIL programmes is not monolithic across Europe (Lasagabaster and Sierra 2010), the characteristics of immersion programmes differ from one context to the next (Tedick and Cammarata 2012). As Dalton-Puffer (2011: 183) suggested, '[w] hether a programme is referred to as immersion or CLIL often depends as much on its cultural and political frame of reference as on the actual characteristics of the program'.

With respect to the observed discourse patterns, even though the CF types appear to be used by teachers in proportionately similar ways across all three contexts, there is evidence of a dynamic interplay between teachers and students in each of the three contexts that led to variable learner response patterns. That is, teachers in each setting were able to shape the context in accordance with their beliefs and experiences; concomitantly, their students were primed by the context to respond accordingly. Whereas learner responses to $\mathrm{CF}$ might be determined by its degree of explicitness (Sheen 2006), explicitness itself is relative and determined to a large extent by contextual variables, such as the instructional context and its overall communicative orientation, which are influenced by teachers and their professional trajectories.

Thus, the observation that JI students responded similarly to all CF types suggests that the JI teachers were adept at integrating a focus on language across the immersion 
curriculum, a skill that may be related to prior teaching experiences: one had taught in Japan and the other in the US as a Japanese teacher at high school and college levels. Moreover, we speculate that teacher-student interaction in JI classes taught by native speakers of Japanese might appear rather formal, given that, as Lyster and Mori (2006) suggested without further exploring in their study, teachers' beliefs and behaviour are inevitably shaped by their professional training and cultural background. What Lyster and Mori did explore - through use of the Communicative Orientation of Language Teaching (COLT) observation scheme (Spada and Fröhlich 1995) - were instructional variables that might make recasts more noticeable in one context than in another. In the JI classrooms - but not the FI classrooms - the COLT scheme detected the use of choral repetition and an emphasis on speaking as a skill practiced in isolation through repetition and reading aloud, which Lyster and Mori suggested may have primed JI students for repeating their teachers' recasts. This would also explain the overall lower percentage of no-uptake moves following CF moves in JI classrooms in comparison with the other two contexts.

In the FI classrooms, the observation that students responded more to prompts than to recasts suggests that their teachers may not have been intentionally using recasts to focus on language and were using prompts to do so instead. As Lyster (1998a) reported, many of the FI teachers' recasts were: (1) indistinguishable from non-corrective repetitions; (2) followed by topic-continuation moves' and (3) accompanied by praise markers (e.g. excellent, bravo). Possibly associated with these patterns is the fact that the teaching experience of three of the four FI teachers prior to immersion was in first language (not second language) classrooms. In addition, recasts might be perceived as more conversational than didactic in FI classrooms specifically in the context of Quebec where teacher-student interaction often unfolds in a conversation-like manner insofar as teachers address young students collectively as their friends ('mes amis') while students address teachers by their first names (often, but not always, preceded by Madame or Monsieur) and usually with informal second-person pronominal forms ('tu'). Moreover, it has been well documented that FI teachers give priority to content over language. One of the first grade FI teachers observed by Salomone (1992: 22) was reported as saying, '[f]rom nine until three-thirty, I do not teach French. I teach subject matter, and French is learned through this content'. Two of the FI teachers in the present study claimed to have only a rough idea of how they focused on language as they interacted with students, because, they both acknowledged, 'their real concern was content' (Lyster 1998b: 74; see also Netten 1991).

In the CLIL classrooms, notwithstanding some similarities with JI classrooms, no choral repetition was observed. Nonetheless, unlike the FI teachers, the CLIL teachers seemed to be more conscious of the language aspect, using didactic recasts and avoiding conversational recasts. This is an interesting finding, given that, unlike the immersion settings, the CLIL data entail only subject matter instruction with no language arts component (CLIL students take a separate EFL course not considered part of the CLIL programme). Here we suggest three possible explanations for the language focus observed in CLIL classrooms. First, in CLIL contexts at the primary level, teachers have been trained to teach not only content areas (math, science and social studies) but also EFL and the two CLIL teachers in the present study indeed taught EFL to their students as well as science and social studies; in addition, they had previous experience as EFL teachers before becoming CLIL teachers. Second, the teachers were non-native speakers of English and, as learners of English themselves, were perhaps sensitive to language issues. Third, the attention they draw to language through didactic recasts may reflect the nature of CLIL itself, which, by definition, is presumed to intentionally integrate both language and content, perhaps more so than has been the case in FI settings. 
What remains unexplained, however, is the CLIL teachers' limited use of prompts and explicit correction along with the limited success of these CF types at eliciting repair in comparison to the immersion contexts. One possible explanation for the difference between CLIL and FI (but not JI) in this regard is that the proficiency level of CLIL students made it difficult for them to respond to CF in the form of prompts and explicit correction, although it remains difficult for us to factor proficiency levels relative to target language exposure as a variable into our comparison, because the FI data in the present study came from two distinct programmes - an early immersion programme (with $80 \%$ French since 1st grade) and a middle immersion programme (with $20 \%$ French since 1 st grade and $60 \%$ French since 4th grade). Noteworthy in this regard, however, is Lyster and Ranta's (1997: 57) observation that the early immersion teacher in their study used recasts considerably less than the middle immersion teachers because, given the higher proficiency levels of her students, she was able 'to push students more in their output and to rely less on the modelling techniques'.

\section{Conclusion}

This study revealed similar patterns across CLIL and immersion classrooms in the proportions of recasts, prompts and explicit correction used by teachers. Learner responses, however, were similar in the CLIL and JI classrooms - with high rates of repair following recasts - but different in the FI classrooms where a greater proportion of repair followed prompts while very little repair followed recasts. We attribute the success of recasts at leading to repair in CLIL and JI classrooms to their didactic and explicit nature and their lack of success in FI classrooms to their conversational and implicit nature. Whether recasts serve a didactic or conversational function in teacher-student interaction is germane to many contextual variables worthy of further pursuit, not the least of which is the professional experience and training of the teachers themselves. The pivotal role of teachers in CBLT was also identified by Lyster and Ballinger (2011) in their examination of 'convergent concerns across divergent contexts' of CBLT in China, Malaysia, Spain and the US. Moreover, they identified an urgent need for professional development to support teachers in meeting the challenges of CBLT.

This study does not support the claim that recasts in meaning-oriented classrooms are ineffective for drawing students' attention to form - at least to the extent that immediate learner repair is a sign of attention. The study does suggest, however, that recasts in such contexts are more effective if delivered intentionally with a didactic purpose rather than solely fulfilling a conversational function. Future research on teachers' beliefs regarding their roles as content and language teachers could offer further insights into their instructional practices and resultant effects on students' integrated learning of both content and language. It would also be interesting to find out whether explicit recasts are as frequent in CLIL classrooms at the secondary level, where teachers are specialists in their content areas with no experience or training as language teachers. Another interesting topic for further research would be to investigate when and why CF moves result in no uptake and whether explanations can be found in the background factors discussed in the present study. In sum, comparing contexts is key for understanding the effect of different interactional patterns on successful second language acquisition.

To conclude, we reiterate that our comparison focused on uptake patterns - specifically drawing attention to differential proportions of learner repair associated with specific $\mathrm{CF}$ types - not to suggest that repair implies language learning, but rather to describe discourse patterns across three different instructional settings. Although at least one quasi- 
experimental study has suggested some long-term advantages for prompts over recasts in immersion classrooms (Lyster 2004), we know of no study that has investigated whether the observed differences in discourse patterns across instructional settings differentially affect target language development. The study by Lyster (2004) was conducted in FI classrooms - a context in which prompts have been observed to lead to more immediate repair than recasts. It would be of interest in future research, therefore, to compare the effects of different types of CF in settings such as CLIL and JI classrooms where the patterns of learner repair have proven to be different.

\section{References}

Allen, P., M. Swain, B. Harley and J. Cummins. 1990. Aspects of classroom treatment: toward a more comprehensive view of second language education. In The Development of Second Language Proficiency, ed. B. Harley, P. Allen, J. Cummins and M. Swain, 57-81. Cambridge: Cambridge University Press.

Ammar, A. and N. Spada. 2006. One size fits all? Recasts, prompts and L2 learning. Studies in Second Language Acquisition 28: 543-574.

Dalton-Puffer, C. 2007. Discourse in Content and Language Integrated Learning (CLIL) Classrooms. Amsterdam/Philadelphia: John Benjamins.

Dalton-Puffer, C. 2011. Content and language integrated learning - from practice to principles? Annual Review of Applied Linguistics 31: 182-204.

Duff, P. 2001. Language, literacy, content, and (pop) culture: challenges for ESL students in mainstream courses. The Canadian Modern Language Review 58: 103-132.

Ellis, R. and Y. Sheen. 2006. Reexamining the role of recasts in second language acquisition. Studies in Second Language Acquisition 28: 575-600.

Genesee, F. 1987. Learning Through Two Languages: Studies of Immersion and Bilingual Children. Cambridge, MA: Newbury House.

Hoare, P. and S. Kong. 2008. Late immersion in Hong Kong: still stressed or making progress? In Pathways to Bilingualism and Multilingualism: Evolving Perspectives on Immersion Education, ed. T. Fortune and D. Tedick, 242-263. Clevedon, UK: Multilingual Matters.

Kong, S. 2009. Content-based instruction: what can we learn from content-trained teachers' and language-trained teachers' pedagogies? The Canadian Modern Language Review 66: 233-269.

Lasagabaster, D. and J.M. Sierra. 2010. Immersion and CLIL in English: more differences than similarities. ELT Journal 64: 367-375.

Llinares, A., T. Morton and R. Whittaker. 2012. The Roles of Language in CLIL. Cambridge: Cambridge University Press.

Loewen, S. and J. Philp. 2006. Recasts in the adult English L2 classroom: characteristics, explicitness, and effectiveness. The Modern Language Journal 90: 536-556.

Long, M.H. 1996. The role of the linguistic environment in second language acquisition. In The Handbook of Second Language Acquisition, ed. W.R. Ritchie and T.K. Bhatia, 413-468. San Diego, CA: Academic Press.

Long, M.H. and P. Robinson. 1998. Focus on form: theory, research, and practice. In Focus on Form in Classroom Second Language Acquisition, ed. C.J. Doughty and J. Williams, 15-41. New York: Cambridge University Press.

Lyster, R. 1998a. Recasts, repetition, and ambiguity in L2 classroom discourse. Studies in Second Language Acquisition 20: 51-81.

Lyster, R. 1998b. Form in immersion classroom discourse: in or out of focus? Canadian Journal of Applied Linguistics 1: 53-82.

Lyster, R. 2004. Differential effects of prompts and recasts in form-focused instruction. Studies in Second Language Acquisition 26: 399-432.

Lyster, R. 2007. Learning and Teaching Languages Through Content: A Counterbalanced Approach. Amsterdam: John Benjamins.

Lyster, R. and S. Ballinger. 2011. Content-based language teaching: convergent concerns across divergent contexts. Language Teaching Research 15: 279-288.

Lyster, R. and H. Mori. 2006. Interactional feedback and instructional counterbalance. Studies in Second Language Acquisition 28: 321-341. 
Lyster, R. and L. Ranta. 1997. Corrective feedback and learner uptake. Studies in Second Language Acquisition 19: 37-66.

Lyster, R., K. Saito and M. Sato. 2013. State-of-the-art article: oral corrective feedback in second language classrooms. Language Teaching 46: 1-40.

Mackey, A., S. Gass and K. McDonough. 2000. How do learners perceive interactional feedback? Studies in Second Language Acquisition 22: 471-497.

Met, M. 1998. Curriculum decision-making in content-based language teaching. In Beyond Bilingualism: Multilingualism and Multilingual Education, ed. J. Cenoz and F. Genesee, 35-63. Clevedon, UK: Multilingual Matters.

Mori, H. 2002. Error treatment sequences in Japanese immersion classroom interactions at different grade levels. Unpublished $\mathrm{PhD}$ diss., University of California.

Musumeci, D. 1996. Teacher-learner negotiation in content-based instruction: communication at cross-purposes? Applied Linguistics 17: 286-325.

Netten, J. 1991. Towards a more language oriented second language classroom. In Language, Culture and Cognition, ed. L. Malavé and G. Duquette, 284-304. Clevedon, UK: Multilingual Matters.

Nicholas, H., P. Lightbown and N. Spada. 2001. Recasts as feedback to language learners. Language Learning 51: 719-758.

O’Donnell, M. 2011. UAM CorpusTool. http://www.wagsoft.com/CorpusTool

Oshima-Takane, Y., B. MacWhinney, H. Sirai, S. Miyata and N. Naka. 1998. CHILDES for Japanese. 2nd ed. Nagoya: Chukyo University, The JCHAT Project.

Salomone, A. 1992. Immersion teachers' pedagogical beliefs and practices: results of a descriptive analysis. In Life in Language Immersion Classrooms, ed. E. Bernhardt, 9-44. Clevedon, UK: Multilingual Matters.

Sato, M. 2011. Constitution of form-orientation: contributions of context and explicit knowledge to learning from recasts. Canadian Journal of Applied Linguistics 14: 1-28.

Sheen, Y. 2004. Corrective feedback and learner uptake in communicative classrooms across instructional settings. Language Teaching Research 8: 263-300.

Sheen, Y. 2006. Exploring the relationship between characteristics of recasts and learner uptake. Language Teaching Research 10: 361-392.

Sheen, Y. and R. Ellis. 2011. Corrective feedback in language teaching. In Handbook of Research in Second Language Teaching and Learning, ed. E. Hinkel, volume 2, 593-610. New York: Routledge.

Spada, N. and M. Fröhlich. 1995. COLT. Communicative Orientation of Language Teaching Observation Scheme: Coding Conventions and Applications. Sydney: National Centre for English Language Teaching and Research.

Swain, M. 1988. Manipulating and complementing content teaching to maximize second language learning. TESL Canada Journal 6: 68-83.

Tedick, D.J. and L. Cammarata. 2012. Content and language integration in K-12 contexts: student outcomes, teacher practices and stakeholder perspectives. Foreign Language Annals 45, no. 1: $28-53$

Thornton, I. and M. Pienemann. 1994. COALA: Computer-Aided Linguistic Analysis. Sydney: Language Acquisition Research Centre.

Yang, Y. and R. Lyster. 2010. Effects of form-focused practice and feedback on Chinese EFL learners' acquisition of regular and irregular past tense forms. Studies in Second Language Acquisition 32: $235-263$. 